\title{
Characteristics of High-density Lipoprotein Subclasses Distribution for Subjects with Desirable Total Cholesterol Levels
}

\author{
$\mathrm{Li} \mathrm{Tian}^{1 \dagger}$, Shiyin Long ${ }^{2 \dagger}$, Mingde $\mathrm{Fu}^{{ }^{*}}$, Yinghui $\mathrm{Liu}^{2}$, Yanhua $\mathrm{Xu}^{3}$ and Lianqun Jia ${ }^{1}$
}

\begin{abstract}
Background: To investigate alteration of high density lipoproteins (HDL) subclasses distribution in different total cholesterol (TC) levels, mainly the characteristics of HDL subclasses distribution in desirable TC levels and analyze the related mechanisms.

Methods: ApoA-I contents of plasma HDL subclasses were determined by 2-dimensional gel electrophoresis coupled with immunodetection. 486 Chinese Adults subjects were assigned to different TC groups according to the third Report of NCEP (ATP- III) guidelines.

Results: The increase in contents of small pre $\beta_{1}-\mathrm{HDL}, \mathrm{HDL}_{3 c}, \mathrm{HDL}_{3 \mathrm{~b}}$, and $\mathrm{HDL}_{3 a}$ particles clustered and reduce in $\mathrm{HDL}_{2 \mathrm{~b}}$ with increased of TC. The distribution of $\mathrm{HDL}$ subclasses have shown abnormality characterized by the lower $\mathrm{HDL}_{2 \mathrm{~b}}(324.2 \mathrm{mg} / \mathrm{L})$ contents and the higher pre $\beta_{1}-\mathrm{HDL}(90.4 \mathrm{mg} / \mathrm{L})$ contents for desirable TC Chinese subjects. Among 176 desirable TC subjects, 58.6\% subjects with triglyceride $(\mathrm{TG})<2.26 \mathrm{mmol} / \mathrm{L}, 61.2 \%$ subjects with $\mathrm{HDL}-\mathrm{C}$ $\geq 1.03 \mathrm{mmol} / \mathrm{L}$ and $88.6 \%$ subjects with low density lipoprotein cholesterol $(\mathrm{LDL}-\mathrm{C})<3.34 \mathrm{mmol} / \mathrm{L}$, and the profile of HDL subclasses distribution for above these subjects was reasonable.

Conclusions: The particles size of HDL subclasses shifted towards smaller with increased TC levels. The TC was liner with $\mathrm{HDL}_{2 \mathrm{~b}}$ contents and those can be reduced $17 \mathrm{mg} / \mathrm{L}$ for $0.5 \mathrm{mmol} / \mathrm{L}$ increment in $\mathrm{TC}$ levels. The $\mathrm{HDL}$ subclasses distribution phenotype was not expectation for Chinese Population with desirable TC levels. Thus, from the $\mathrm{HDL}$ subclasses distribution point, when assessing the coronary heart disease(CHD) risk not only rely on the TC levels, but also the concentrations of TG, HDL-C and LDL-C must considered in case the potential risk for desirable TC subjects with other plasma lipids metabolism disorders.
\end{abstract}

\section{Introduction}

Cholesterol is a fat-like substance used to help build cell membranes, make some hormones, and form bile secretions that aid in digestion. cholesterol's most important job is to help carry fat through your blood vessels. Cholesterol travels in the blood in distinct particles containing both lipid and proteins (lipoproteins). Classical concepts of the regulation of plasma cholesterol levels involve roles for the "forward" delivery of low density lipoprotein cholesterol (LDL-C) from the liver to the peripheral tissues, mediated by the LDL receptor, and a

\footnotetext{
* Correspondence: Apolipoprotein2009@yahoo.com.cn

+ Contributed equally

'Laboratory of Endocrinology and Metabolism, West China Hospital, Sichuan University, Chengdu 610041, Sichuan, People's Republic of China

Full list of author information is available at the end of the article
}

"reverse" delivery of cholesterol in the form of high density lipoproteins (HDL) from the peripheral tissues to the liver [1]. The amount of HDL and LDL in the blood is added together, this number for all practical purposes, indicates the amount of total cholesterol (TC).

LDL-C is the primary transport carrier of cholesterol in the circulation. A broad base of evidence indicates that elevations in LDL cholesterol are a direct cause of atherosclerosis. Long-term elevations of LDL cholesterol lead to a progressive accumulation of coronary atherosclerosis [2]. Thus, LDL-C is proposed to be more highly associated with coronary heart disease (CHD) [3].

HDL-C normally makes up $20-30 \%$ of the TC and it prevents the uptake of LDL-C at receptor sites in the body and participates in the metabolism of other lipoproteins. Strong epidemiological evidence links low

\section{C) Biomed Central}


levels of serum HDL cholesterol to increased CHD morbidity and mortality. High HDL-C levels conversely convey reduced risk [4-6]. Epidemiological data taken as a whole signify that a 1 percent decrease in HDL cholesterol is associated with a $2-3$ percent increase in CHD risk.

HDL is highly heterogeneous, with subclasses that can be identified on the basis of density, size, charge, and protein composition [7] and using two-dimensional gel electrophoresis coupled with immunoblotting, HDL can be divided into large, cholesterol-rich $\left(\mathrm{HDL}_{2 \mathrm{a}}\right.$ and $\left.\mathrm{HDL}_{2 \mathrm{~b}}\right)$, small, lipid-poor $\left(\mathrm{HDL}_{3 \mathrm{c}}, \mathrm{HDL}_{3 \mathrm{~b}}, \mathrm{HDL}_{3 \mathrm{a}}\right.$, and pre $\beta_{1}$-HDL) and pre $\beta_{2}$-HDL. We have previously investigated the impact of plasma triglyceride (TG), TC, LDL-C and HDL-C levels on HDL subclass distribution, and found that the particle size of HDL shifted towards smaller size as the rise of plasma TG, TC, LDL-C levels, or the fall of HDL-C levels [8-11].

Thus, in this work, we mainly assessed that the effect of TC levels on HDL subclasses distribution, especially the characteristics of HDL subclasses distribution for subjects with desirable TC levels [12].

\section{Materials and methods Subjects}

Four hundred and eighty-six subjects, aged 33 to 78 years $(56.1 \pm 8.4)$, were recruited to participate in a study examining plasma lipid and apolipoprotein concentrations. were recruited to participate in a study examining plasma lipid and apo concentrations at West China Medical Center, Sichuan University. These subjects were from the Sichuan University and Sichuan Normal University, in Chengdu, Sichuan province, PR China, in which female were 198 and male were 288. Exclusion criteria were the following: (1) the presence of nephrosis, diabetes mellitus, hypothyroidism, or hepatic impairment; (2) the presence of a major cardiovascular event (myocardial infarction, severe or unstable angina pectoris, and surgery) or stroke; (3) taking lipid-altering medications; or (4) a history of alcohol abuse and smoking cigarettes. Women who had undergone a hysterectomy with or without an oophorectomy were excluded from the study, and for postmenopausal female subjects, none were receiving hormone replacement therapy. Informed consent was obtained from each subject upon entry into the study population. This study protocol was approved by the ethics committee.

To study the relationship between the TC levels and HDL subclass distribution, we divided these subjects into three subgroups using the Adult Treatment Panel (ATP-III) guidelines for TC defined, that is, desirable TC (<5.17 mmol/L), borderline-high TC (5.17-6.18 $\mathrm{mmol} / \mathrm{L})$, high TC ( $\geq 5.17 \mathrm{mmol} / \mathrm{L})$ [12]. Moreover, individuals were classified according to approximately equal ninths of baseline TC for the entire study population, and observed the levels of TC change and degree of major HDL subclasses alteration.

\section{Specimens}

Whole blood specimens were drawn after a 12 hours overnight fast into EDTA-containing tubes. Plasma was separated within 1-2 hour. Plasma was stored at $4^{\circ} \mathrm{C}$ and used for lipid and apo analyses within 24 hours. An aliquot of plasma was stored at $-70^{\circ} \mathrm{C}$ for the determination of HDL subclasses.

\section{Plasma lipid and apolipoprotein analyses}

Plasma TG, TC and HDL-C concentrations were measured by the standard technique. TC and TG were determined with enzymatic kits (Beijing Zhongsheng Biotechnological Corporation, Beijing, and People's Republic of China). The HDL-C was determined after precipitation of the apoB-containing lipoproteins by phosphotungstate/magnesium chloride [13]. LDL-C was calculated using the Friedwald formula (TG $<4.52$ $\mathrm{mmol} / \mathrm{L}$ ) [14]. When plasma TG was at least 4.52 $\mathrm{mmol} / \mathrm{L}$, LDL-C was determined following the precipitation method with polyvinylsulfate (enzymatic kits). Plasma apoA-I, B-100, C-II, and C-III were determined by radial immunodiffusion methods [15] using kits developed at the Apolipoprotein Research Laboratory, West China Medical Center, Sichuan University. The intraassay coefficient of variation for apo concentrations was between $2.1 \%$ and $4.8 \%$; the interassay coefficient of variation was $3.5 \%$ to $7.9 \%$ [16].

\section{High density lipoprotein cholesterol subclass analysis}

ApoA-I-containing HDL subclasses were measured by nondenaturing two-dimensional gel electrophoresis associated with the immunodetection method, as described previously [17]. Briefly, $10 \mu \mathrm{l}$ of plasma was first separated by charge on $0.7 \%$ agarose gel into pre $\beta$ and $\alpha$ mobility particles. In the second dimension, the two fractions of HDL were further separated according to size by $2-30 \%$ nondenaturing polyacrylamide gradient gel electrophoresis. To determine HDL subclasses, Western blotting was conducted after 2-D gel electrophoretic, plasma proteins and molecular markers were electroretically transferred to PVDF membranes, stained with $0.1 \%$ ponceau $S$, and the position of molecular standard protein bands labeled by pencil, and destained by diffusion, then using $5 \%$ bovine serum albumin(BSA) recovered the membrane, following interaction with horseradish peroxidase (HRP)-labeled goat antihuman apo A-I immunoglobulin G. The HDL particle sizes were calibrated using a standard curve that included bovine serum albumin, ferritin and thyroglobulin (Pharmacia, Uppsala, Sweden). The calculation of the relative 
percentage of each HDL subclass was based on the density of the electrophoresis spots. Then, the apoA-I contents (in milligrams per liter) of the HDL subclasses were calculated by multiplying the percentage of each subclass by the plasma total apoA-I concentrations. The interassay coefficients of variation of the relative concentration of pre $\beta_{1}-\mathrm{HDL}$, pre $\beta_{2}-\mathrm{HDL}, \mathrm{HDL}_{3 \mathrm{c}}, \mathrm{HDL}_{3 \mathrm{~b}}$, $\mathrm{HDL}_{3 \mathrm{a}}, \mathrm{HDL}_{2 \mathrm{a}}$, and $\mathrm{HDL}_{2 \mathrm{~b}}$ in the plasma sample were $9.4 \%, 9.8 \%, 4.9 \%, 6.2 \%, 7.3 \%, 11.1 \%$ and $7.9 \%$, respectively $(\mathrm{n}=5)$.

\section{Statistical analysis}

Kolmogorov-Smirnov statistics was used to test normality of distributions of plasma lipids and HDL subclasses. For analysis, non-Gaussian-distributed data were transformed using the natural logarithm to approach a Gaussian distribution. All statistical analyses were performed using the statistical package SPSS Version 13.0 (SPSS, Chicago, IL). Data in the tables are expressed as mean \pm S.D. The Duncan posthoc test was used in situations in which a significant group (one-way analysis of variance) effect was observed. Two-way ANOVA was performed to evaluate the interactive effects of TG and TC on HDL subclasses distribution. Pearson correlation coefficients were calculated to quantitatively analyze the associations among variables adjusted for TG concentration. In all comparisons, $P$ less than 0.05 (2-sided) represented a statistically significant difference.

\section{Results}

Relations of the pre $\beta_{1}-\mathrm{HDL}$ and $\mathrm{HDL}_{2 b}$ contents and change in the levels of TC

To investigate the degree of major HDL subclasses change with the levels of TC, varied, we divided the levels of TC into 9 strata and using each stratum TC median value as $\mathrm{x}$ axis, with every stratum $\mathrm{TC}$ corresponding the median pre $\beta_{1}-\mathrm{HDL}$ and $\mathrm{HDL}_{2 \mathrm{~b}}$ contents as y axis to plot (Figure 1). The figure shows associations of $\mathrm{TC}$ levels with decreased $\mathrm{HDL}_{2 \mathrm{~b}}$ contents.

The concentrations of plasma lipids, lipoproteins, and apolipoproteins along with their ratios among subjects categorized by TC concentration

Table 1 reports baseline demographic and plasma levels of lipids, lipoproteins, and apolipoproteins as well as their ratios for subjects in each TC subgroup. Subjects in desirable and borderline-high TC subgroups were somewhat younger than those included in high $\mathrm{TC}$ subgroup. Concentrations of TG, TC, LDL-C, HDL-C, and apoB-100, C-II, C-III along with the ratios of TC/HDLC, LDL-C/HDL-C and apoB-100/A-I were substantially lower in desirable and borderline-high TC subgroups than those in high TC subgroup.

The apolipoprotein A-I contents of HDL subclasses according to the TC concentration

Table 2 displays the characteristics of HDL subclasses contents for subjects in per TC subgroup. We observed

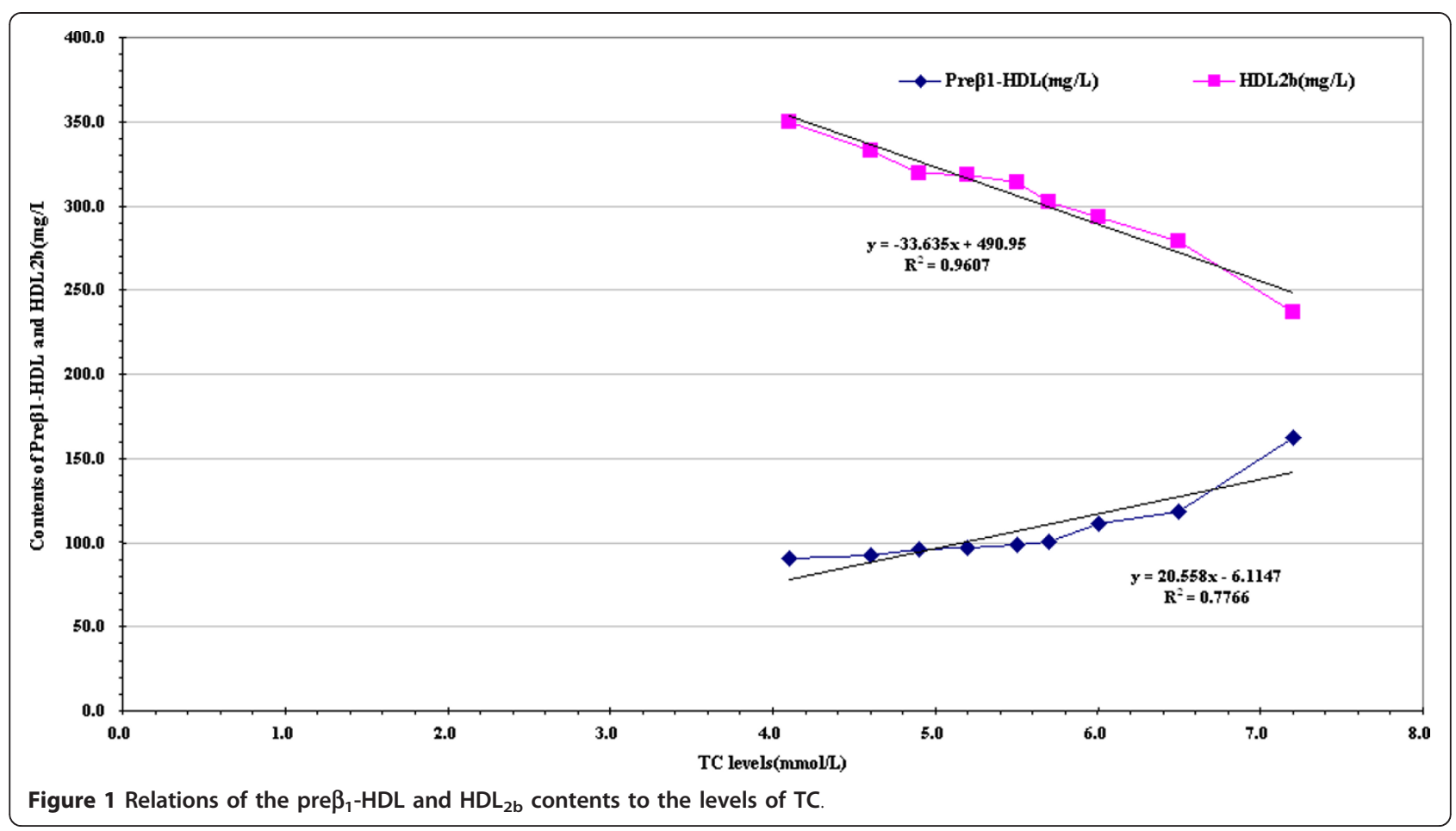


Table 1 The concentrations of plasma lipids, lipoproteins, and apolipoproteins their ratios among subjects categorized by TC levels

\begin{tabular}{|c|c|c|c|}
\hline & $\begin{array}{c}\text { Desirable TC } \\
(n=176)\end{array}$ & $\begin{array}{l}\text { Borderline high-TC } \\
\quad(n=194)\end{array}$ & $\begin{array}{l}\text { High TC } \\
(n=116)\end{array}$ \\
\hline Age(yr) & $54.9 \pm 8.3$ & $57.2 \pm 9.3^{\text {af }}$ & $58.6 \pm 9.2^{\mathrm{a} \S}$ \\
\hline $\operatorname{BMI}\left(\mathrm{kg} / \mathrm{m}^{2}\right)$ & $23.3 \pm 2.4$ & $23.8 \pm 2.3$ & $23.2 \pm 2.9^{a \S b \S}$ \\
\hline $\mathrm{TG}(\mathrm{mmol} / \mathrm{L})$ & $1.9 \pm 0.2$ & $2.2 \pm 0.4$ & $2.4 \pm 0.5^{\mathrm{a} \neq}$ \\
\hline $\mathrm{TC}(\mathrm{mmol} / \mathrm{L})$ & $4.6 \pm 0.4$ & $5.6 \pm 0.3^{a \neq}$ & $6.8 \pm 0.4^{a \S b \neq}$ \\
\hline $\mathrm{LDL}-\mathrm{C}(\mathrm{mmol} / \mathrm{L})$ & $2.5 \pm 0.4$ & $3.3 \pm 0.6^{\mathrm{a} f}$ & $4.4 \pm 0.7^{\mathrm{aSb} *}$ \\
\hline $\mathrm{HDL}-\mathrm{C}(\mathrm{mmol} / \mathrm{L})$ & $1.1 \pm 0.2$ & $1.2 \pm 0.3$ & $1.3 \pm 0.4^{a *}$ \\
\hline ApoA-I(mg/L) & $1210.7 \pm 168.6$ & $1282.2 \pm 179.1$ & $1280.8 \pm 171.6$ \\
\hline ApoB-100(mg/L) & $769.6 \pm 96.4$ & $925.3 \pm 108.3^{\mathrm{a} \neq}$ & $1081.4 \pm 128.2^{a \S b \neq}$ \\
\hline ApoC-II(mg/L) & $55.1 \pm 10.3$ & $70.1 \pm 12.7^{\mathrm{a} *}$ & $79.2 \pm 11.8^{\mathrm{a} *}$ \\
\hline ApoC-III(mg/L) & $129.1 \pm 20.6$ & $157.5 \pm 22.6^{\mathrm{a} *}$ & $180.2 \pm 32.6^{a \S b *}$ \\
\hline TG/HDL-C & $2.0 \pm 0.3$ & $2.2 \pm 0.2$ & $2.2 \pm 0.3$ \\
\hline TC/HDL-C & $4.2 \pm 1.0$ & $5.0 \pm 1.0^{\mathrm{a} \neq}$ & $5.5 \pm 1.1^{\mathrm{a} s \mathrm{~b}_{*}}$ \\
\hline LDL-C/HDL-C & $2.3 \pm 0.4$ & $2.9 \pm 0.7^{a *}$ & $3.5 \pm 0.9^{\mathrm{a} s \mathrm{~b} \neq}$ \\
\hline ApoB-100/A-I & $0.7 \pm 0.2$ & $0.7 \pm 0.2$ & $0.9 \pm 0.3^{\mathrm{a}^{*}} \mathrm{~b}_{*}$ \\
\hline
\end{tabular}

Values are expressed as Mean \pm S.D

${ }^{\text {a }}$ Compared with Desirable TC

${ }^{\mathrm{b}}$ Compared with Borderline high-TC

${ }^{*} P<0.05,{ }^{\ddagger} P<0.01,{ }^{\S} P<0.001$

TC, total cholesterol; BMI, body mass index; TG, triglyceride; LDL-C, low density lipoprotein cholesterol; HDL-C, high density lipoprotein cholesterol; ApoA-I, B-100, C-II, C-III, apolipoproteinA-I, B-100, C-II, C-III.

that increases in the contents of small pre $\beta_{1}-\mathrm{HDL}$, $\mathrm{HDL}_{3 \mathrm{c}}, \mathrm{HDL}_{3 \mathrm{~b}}$, and $\mathrm{HDL}_{3 \mathrm{a}}$ particles clustered with the increases in TC concentration. When compared with the subject in high TC subgroup, the subjects in both borderline-high and desirable TC subgroups had higher contents of large $\mathrm{HDL}_{2 \mathrm{a}}$ and $\mathrm{HDL}_{2 \mathrm{~b}}$ particles. However, large sized $\mathrm{HDL}_{2}$ particles kept the lower levels for subjects in desirable TC subgroup.

Frequency distribution of the subjects according to the concentrations of TG and HDL-C for subjects with desirable TC levels

To further understand the profile of HDL subclasses distribution in different levels of TG and HDL-C for subjects with desirable TC, we using the ATP-III set the
$1.03,1.52 \mathrm{mmol} / \mathrm{L}$ for HDL-C and $2.26 \mathrm{mmol} / \mathrm{L}$ for TG as cut-points to divided these subjects (Figure 2).

Figure 2 presented that there were 51 subjects (29.1\%) with TG $\geq 2.26 \mathrm{mmol} / \mathrm{L}-\mathrm{HDL}-\mathrm{C}<1.03 \mathrm{mmol} / \mathrm{L}$, and only $14.8 \%$ (26) subjects with TG $<2.26 \mathrm{mmol} / \mathrm{L}-\mathrm{HDL}-$ $\mathrm{C} \geq 1.55 \mathrm{mmol} / \mathrm{L}$ in desirable TC levels. Moreover, in the desirable TC levels, the subjects with $\mathrm{TG} \geq 2.26$ $\mathrm{mmol} / \mathrm{L}$ occupied approximately $41.4 \%$, and $38.8 \%$ subjects with HDL-C $<1.03 \mathrm{mmol} / \mathrm{L}$.

The apolipoprotein A-I contents of HDL subclasses according to the TG or HDL-C concentrations in desirable TC subjects

As shown in Table 3, in desirable TC subjects, the contents of pre $\beta_{1}-\mathrm{HDL}, \mathrm{HDL}_{3 \mathrm{~b}}$, and $\mathrm{HDL}_{3 \mathrm{a}}$ in $\mathrm{TG}<2.26$

Table 2 The apoA-I contents of HDL subclasses among the subjects according to the TC levels

\begin{tabular}{|c|c|c|c|}
\hline & $\begin{array}{c}\text { Desirable TC } \\
(n=176)\end{array}$ & $\begin{array}{l}\text { Borderline high-TC } \\
\quad(\mathrm{n}=194)\end{array}$ & $\begin{array}{l}\text { High TC } \\
(n=116)\end{array}$ \\
\hline Pre $\beta_{1}-\mathrm{HDL}(\mathrm{mg} / \mathrm{L})$ & $90.4 \pm 15.3$ & $102.2 \pm 20.8$ & $135.8 \pm 24.9^{\mathrm{a} s b_{*}}$ \\
\hline Pre $\beta_{2}-\mathrm{HDL}(\mathrm{mg} / \mathrm{L})$ & $53.5 \pm 8.4$ & $63.4 \pm 9.1$ & $70.0 \pm 11.6^{\mathrm{a} *}$ \\
\hline $\mathrm{HDL}_{3 \mathrm{c}}(\mathrm{mg} / \mathrm{L})$ & $69.1 \pm 7.6$ & $73.9 \pm 8.6$ & $82.7 \pm 10.5$ \\
\hline $\mathrm{HDL}_{3 \mathrm{~b}}(\mathrm{mg} / \mathrm{L})$ & $135.9 \pm 21.5$ & $145.6 \pm 22.3$ & $172.7 \pm 28.6^{\mathrm{a} \mathrm{b}_{*}}$ \\
\hline $\mathrm{HDL}_{3 \mathrm{a}}(\mathrm{mg} / \mathrm{L})$ & $281.9 \pm 29.2$ & $298.2 \pm 24.2^{\mathrm{a} *}$ & $319.3 \pm 30.1^{a \S b_{*}}$ \\
\hline $\mathrm{HDL}_{2 \mathrm{a}}(\mathrm{mg} / \mathrm{L})$ & $257.2 \pm 20.1$ & $259.9 \pm 18.3$ & $251.6 \pm 21.5$ \\
\hline $\mathrm{HDL}_{2 \mathrm{~b}}(\mathrm{mg} / \mathrm{L})$ & $324.2 \pm 30.3$ & $337.5 \pm 35.3$ & $281.7 \pm 29.9^{a \S b \S}$ \\
\hline
\end{tabular}

Values are expressed as Mean \pm S.D

${ }^{a}$ Compared with Desirable TC group

${ }^{\mathrm{b}}$ Compared with Borderline high-TC group

${ }^{*} P<0.05,{ }^{\ddagger} P<0.01,{ }^{\S} P<0.001$

$\mathrm{TC}$, total cholesterol; $\mathrm{HDL}_{3 \mathrm{c}} 3 \mathrm{~b}$, 3ar $2 \mathrm{a}, 2 \mathrm{~b}$, high density lipoproteins $\mathrm{s}_{3 \mathrm{c}}, 3 \mathrm{~b}, 3 \mathrm{a}, 2 \mathrm{a}, 2 \mathrm{~b}$ 


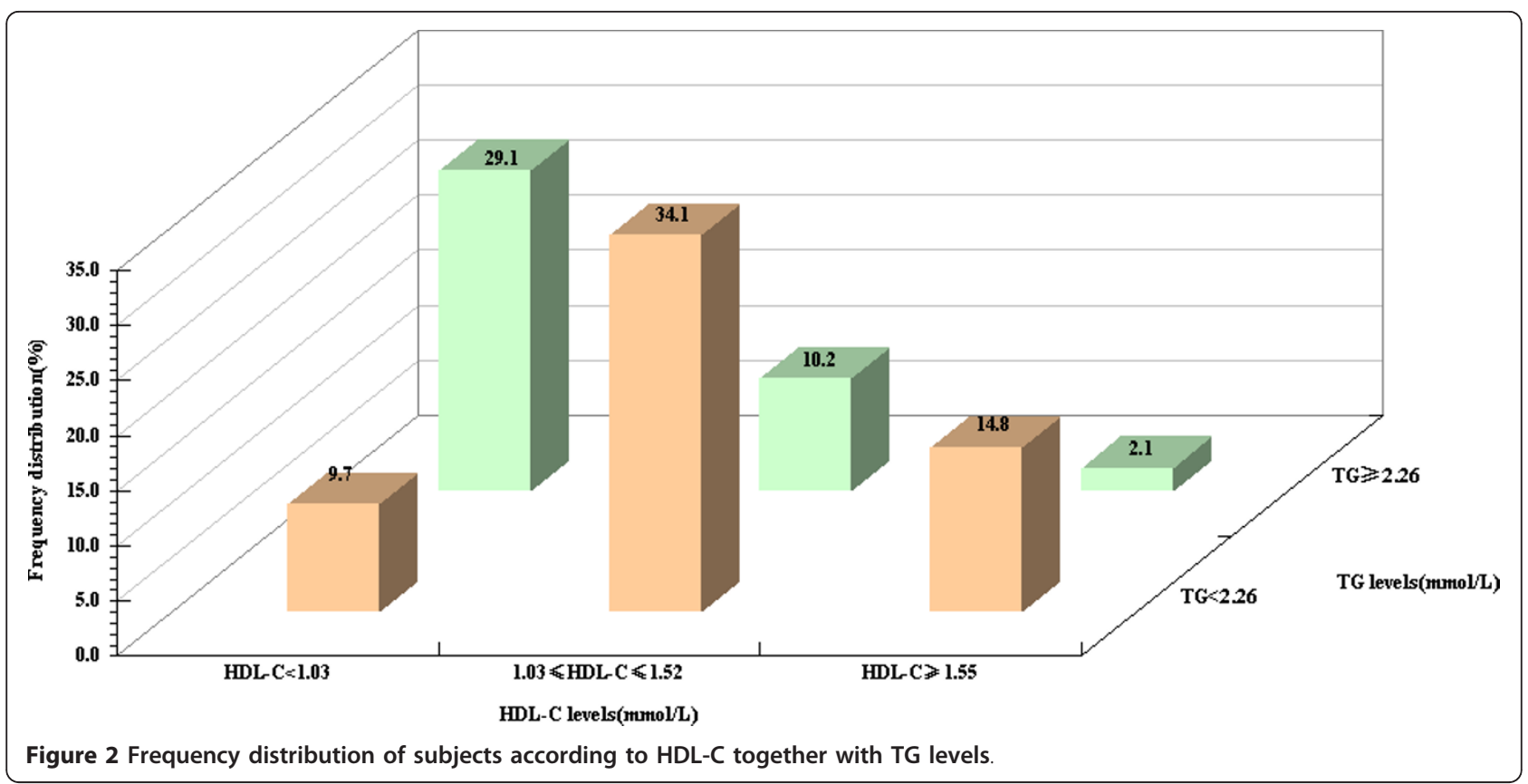

$\mathrm{mmol} / \mathrm{L}$ subgroup were significantly lower than TG $\geq$ $2.26 \mathrm{mmol} / \mathrm{L}$ subgroup $(P<0.001)$. In contrast, those of $\mathrm{HDL}_{2 \mathrm{a}}$ and $\mathrm{HDL}_{2 \mathrm{~b}}$ in $\mathrm{TG}<2.26 \mathrm{mmol} / \mathrm{L}$ subgroup were significantly higher than $\mathrm{TG} \geq 2.26 \mathrm{mmol} / \mathrm{L}$ subgroup $(P<0.001)$. Likewise, compared to the subjects with HDL-C $<1.03 \mathrm{mmol} / \mathrm{L}$, the characteristics of HDL subclasses distribution in subjects with HDL-C $\geq 1.03$ $\mathrm{mmol} / \mathrm{L}$ was accord with that in subjects with $\mathrm{TG}<$ $2.26 \mathrm{mmol} / \mathrm{L}$.

The apolipoprotein A-I contents of HDL subclasses according to the LDL-C concentrations in desirable TC subjects

Table 4 showed that in comparison with the subjects with $\mathrm{LDL}-\mathrm{C}<3.34 \mathrm{mmol} / \mathrm{L}$, the subjects with $\mathrm{LDL}-\mathrm{C} \geq$ $3.34 \mathrm{mmol} / \mathrm{L}$ had higher contents of $\mathrm{HDL}_{3 \mathrm{~b}}, \mathrm{HDL}_{3 \mathrm{a}}$ and lower contents of $\mathrm{HDL}_{2 \mathrm{a}}$ and $\mathrm{HDL}_{2 \mathrm{~b}}$ in desirable $\mathrm{TC}$ levels.

Relationships among plasma lipids, lipoproteins, apolipoproteins and HDL subclasses contents (Controlling for TG)

After adjustment for TG, the TC concentration was positively related to pre $\beta_{1}-\mathrm{HDL}$, pre $\beta_{2}-\mathrm{HDL}, \mathrm{HDL}_{3}$ $\left(\mathrm{HDL}_{3 \mathrm{c}}, \mathrm{HDL}_{3 \mathrm{~b}}\right.$, and $\mathrm{HDL}_{3 \mathrm{a}}$ ) and negatively related to $\mathrm{HDL}_{2}\left(\mathrm{HDL}_{2 \mathrm{a}}\right.$ and $\left.\mathrm{HDL}_{2 \mathrm{~b}}\right)$. The relationship for LDL-C and apoB-100 showed a significant positive with pre $\beta_{1}$ $\mathrm{HDL}, \mathrm{HDL}_{3 \mathrm{c}}, \mathrm{HDL}_{3 \mathrm{~b}}$ but inverse with $\mathrm{HDL}_{2 \mathrm{~b}}$. The apoA-I levels were strong association with all HDL subclasses. Meanwhile, a significant correlation between the pre $\beta_{1}-\mathrm{HDL}, \mathrm{HDL}_{3 \mathrm{c}}, \mathrm{HDL}_{3 \mathrm{~b}}, \mathrm{HDL}_{2}$ and $\mathrm{HDL}-\mathrm{C}$ was observed (Table 5). The 2-way ANOVA results indicated

Table 3 The apoA-I contents of HDL subclasses among the desirable TC subjects in accordance with TG along with HDL-C levels

\begin{tabular}{|c|c|c|c|c|}
\hline & \multicolumn{2}{|c|}{ Desirable TC } & \multicolumn{2}{|c|}{ Desirable TC } \\
\hline & TG $<2.26(n=103)$ & $T G \geq 2.26(n=73)$ & HDL-C $<1.03(n=69)$ & HDL-C $\geq 1.03(n=107)$ \\
\hline Pre $\beta_{1}-\mathrm{HDL}(\mathrm{mg} / \mathrm{L})$ & $79.3 \pm 10.7$ & $118.1 \pm 21.4^{\S}$ & $115.4 \pm 11.5$ & $83.1 \pm 8.1^{\ddagger}$ \\
\hline Pre $\beta_{2}-\mathrm{HDL}(\mathrm{mg} / \mathrm{L})$ & $50.6 \pm 8.1$ & $56.1 \pm 9.2$ & $53.4 \pm 4.2$ & $54.5 \pm 4.7$ \\
\hline $\mathrm{HDL}_{3 c}(\mathrm{mg} / \mathrm{L})$ & $63.6 \pm 8.6$ & $72.2 \pm 10.9$ & $72.2 \pm 8.4$ & $64.0 \pm 5.8$ \\
\hline $\mathrm{HDL}_{3 b}(\mathrm{mg} / \mathrm{L})$ & $105.2 \pm 28.9$ & $146.9 \pm 30.2^{\S}$ & $146.5 \pm 19.6$ & $128.4 \pm 17.4$ \\
\hline $\mathrm{HDL}_{3 \mathrm{a}}(\mathrm{mg} / \mathrm{L})$ & $258.2 \pm 30.4$ & $315.3 \pm 40.9^{\S}$ & $297.6 \pm 28.9$ & $274.1 \pm 20.5^{*}$ \\
\hline $\mathrm{HDL}_{2 \mathrm{a}}(\mathrm{mg} / \mathrm{L})$ & $268.6 \pm 35.3$ & $226.7 \pm 29.7^{\S}$ & $222.8 \pm 20.7$ & $272.6 \pm 21.5^{\S}$ \\
\hline $\mathrm{HDL}_{2 b}(\mathrm{mg} / \mathrm{L})$ & $381.9 \pm 50.5$ & $242.8 \pm 29.9^{\S}$ & $247.6 \pm 25.1$ & $371.3 \pm 40.6^{\S}$ \\
\hline
\end{tabular}

Values are expressed as Mean \pm S.D

Compared with the corresponding low levels group

${ }^{*} P<0.05,{ }^{\ddagger} P<0.01,{ }^{\S} P<0.001$

TC, total cholesterol; TG, triglyceride; $\mathrm{HDL}_{3 c}, 3 b, 3 a, 2 a, 2 b$, high density lipoproteins $3 c, 3 b, 3 a, 2 a, 2 b$. 
Table 4 The apoA-I contents of HDL subclasses among the desirable TC subjects in accordance with LDL-C levels

\begin{tabular}{|c|c|c|}
\hline & \multicolumn{2}{|c|}{ Desirable TC } \\
\hline & LDL-C $<3.34(n=156)$ & LDL-C $\geq 3.34(n=20)$ \\
\hline $\operatorname{Pre} \beta_{1}-\mathrm{HDL}(\mathrm{mg} / \mathrm{L})$ & $84.3 \pm 8.0$ & $110.8 \pm 8.2^{*}$ \\
\hline $\operatorname{Pre} \beta_{2}-\mathrm{HDL}(\mathrm{mg} / \mathrm{L})$ & $50.8 \pm 3.2$ & $53.6 \pm 3.7$ \\
\hline $\mathrm{HDL}_{3 \mathrm{c}}(\mathrm{mg} / \mathrm{L})$ & $59.1 \pm 5.4$ & $69.6 \pm 6.1$ \\
\hline $\mathrm{HDL}_{3 b}(\mathrm{mg} / \mathrm{L})$ & $135.3 \pm 18.9$ & $153.2 \pm 20.1^{*}$ \\
\hline $\mathrm{HDL}_{3 \mathrm{a}}(\mathrm{mg} / \mathrm{L})$ & $263.5 \pm 26.9$ & $282.8 \pm 29.2^{*}$ \\
\hline $\mathrm{HDL}_{2 \mathrm{a}}(\mathrm{mg} / \mathrm{L})$ & $288.1 \pm 27.5$ & $249.5 \pm 20.4^{\S}$ \\
\hline $\mathrm{HDL}_{2 \mathrm{~b}}(\mathrm{mg} / \mathrm{L})$ & $370.6 \pm 39.9$ & $252.0 \pm 30.8^{\S}$ \\
\hline
\end{tabular}

Values are expressed as Mean \pm S.D

Compared with the corresponding low levels group

${ }^{*} P<0.05,{ }^{\S} P<0.001$

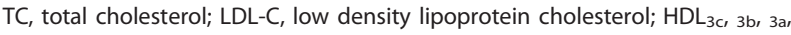
$2 a, 2 b$, high density lipoprotein $s_{3 c, 3} 3 b, 3 a r 2 a r 2 b$.

that there were significant interaction of $\mathrm{TC}$ and $\mathrm{TG}$ effect on pre $\beta_{2}-\mathrm{HDL}, \mathrm{HDL}_{3 \mathrm{c}}, \mathrm{HDL}_{3 \mathrm{~b}}, \mathrm{HDL}_{3 \mathrm{a}}$, and $\mathrm{HDL}_{2 \mathrm{a}}$ (Table 6).

\section{Discussion}

Numerous observational studies have demonstrated that a strong, continuous, graded, and independent association between cholesterol and the risk of CHD. A high $\mathrm{TC}$ is a marker for atherogenic lipoproteins. The elevated plasma TC contributes to coronary atherosclerosis throughout life; which measured in young adulthood correlate with CHD rates later in life and over a lifetime. Increased lifetime risks associated with high $\mathrm{TC}$ levels ( $\geq 6.21 \mathrm{mmol} / \mathrm{L}$ ) are clearly evident and justify clinical therapies to reduce long-term risk. But even borderlinehigh TC (5.17-6.18 mmol/L) carries significant longterm risk, and it deserves clinical intervention [18-22]. In this regard, only TC levels $<5.17 \mathrm{mmol} / \mathrm{L}$ was expectation for Western people.

Population studies have shown a highly consistent, inverse correlation between plasma concentrations of

Table 5 The correlation analysis between lipids, lipoproteins, and apoA-I contents of HDL subclasses (Controlling for TG)

\begin{tabular}{|c|c|c|c|c|c|c|c|c|c|c|}
\hline & \multicolumn{2}{|l|}{ TC } & \multicolumn{2}{|c|}{ LDL-C } & \multicolumn{2}{|c|}{ HDL-C } & \multicolumn{2}{|c|}{ ApoA-I } & \multicolumn{2}{|c|}{ ApoB-100 } \\
\hline & 6 & $P$ & 6 & $P$ & 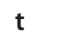 & $r$ & 6 & $P$ & 6 & $r$ \\
\hline$e \beta$ & .390 & .000 & .381 & .000 & .063 & .169 & .491 & .000 & .183 & .000 \\
\hline$e \beta_{2}-H D L$ & .136 & .003 & .077 & .089 & .165 & .000 & .489 & .000 & -.008 & .867 \\
\hline Q1 & .217 & .000 & .156 & .001 & .193 & .000 & .360 & .000 & .112 & .013 \\
\hline & .296 & & & & 40 & & 23 & 00 & 4 & 022 \\
\hline & .091 & .045 & .075 & .100 & .058 & .204 & .567 & .000 & .045 & .322 \\
\hline & -.130 & .004 & -.128 & .005 & .200 & .000 & .558 & .000 & -.031 & .494 \\
\hline $\mathrm{DL}_{2 \mathrm{~b}}$ & -.136 & .003 & -.216 & .000 & .286 & .000 & .415 & .000 & -.168 & .000 \\
\hline
\end{tabular}

TG, triglyceride; TC, total cholesterol; LDL-C, low density lipoprotein cholesterol, ApoA-I, B-100, apolipoproteinA-I, B-100; HDL $3 c$, 3b, 3a, 2ar 2b, high density lipoproteins $\mathrm{sc}_{3 \mathrm{r}} \mathrm{b}$, 3ar $2 \mathrm{ar} 2 \mathrm{~b}$.
Table $6 \boldsymbol{P}$ values calculated by 2 -way ANOVA for HDL subclasses

\begin{tabular}{|c|c|c|c|}
\hline & $\begin{array}{l}\text { Factor A } \\
\text { (TC) }\end{array}$ & $\begin{array}{c}\text { Factor B } \\
\text { (TG) }\end{array}$ & $\begin{array}{c}\text { Factor interaction } \\
(\mathrm{TC} \times \mathrm{TG})\end{array}$ \\
\hline Pre $\beta_{1}$-HDL & .000 & .000 & .000 \\
\hline Pre $\beta_{2}-\mathrm{HDL}$ & .002 & .042 & .003 \\
\hline $\mathrm{HDL}_{3 \mathrm{c}}$ & .000 & .192 & .084 \\
\hline $\mathrm{HDL}_{3 b}$ & .000 & .369 & .296 \\
\hline $\mathrm{HDL}_{3 a}$ & .279 & .001 & .006 \\
\hline $\mathrm{HDL}_{2 \mathrm{a}}$ & .665 & .000 & .217 \\
\hline $\mathrm{HDL}_{2 b}$ & .000 & .000 & .000 \\
\hline
\end{tabular}

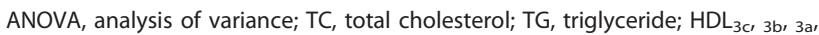
$2 a r 2 b$, high density lipoproteins $3 c, 3 b, 3 a r 2 a r 2$.

HDL-C and atherosclerotic cardiovascular disease risk in humans [23] and the concept that certain subfractions of HDL may be better predictors of cardiovascular risk is attractive [11]. Asztalos et al. [24] found that large $\alpha$ $1 \mathrm{HDL}\left(\mathrm{HDL}_{2 \mathrm{~b}}\right)$ was most significantly associated with CHD prevalence, and their study demonstrated that each milligram per decaliter increase in $\alpha-1$ HDL level decreased the odds of CHD by $26 \%$ in a model including all established CHD risk factors. Thus, HDL lipoprotein subfraction tests may be useful to help determine the need to treat patients at intermediate risk for CHD as determined by more conventional tests [25-32]. Epidemiological investigations have established that a high level of LDL-C is a major risk factor for developing $\mathrm{CHD}$. For persons without other CHD risk factors, risk for CHD is relatively low when LDL-C levels are $<3.34$ $\mathrm{mmol} / \mathrm{L}$. However, although the availability the effective of LDL-C lowering therapies, many patients continue to develop CHD and the contributions of other plasma lipids and lipoprotein subclasses to the risk of CHD is increasingly being recognized.

In current work, for grouped analyses, individuals were classified according to approximately equal ninths of baseline TC for the entire study population (Figure $1)$. Trends in mean values of major HDL subclasses (pre $\beta_{1}-\mathrm{HDL}$ and $\mathrm{HDL}_{2 \mathrm{~b}}$ ) across these ninths were assessed through simple linear regression, in these models with the contents of pre $\beta_{1}-\mathrm{HDL}$ and $\mathrm{HDL}_{2 \mathrm{~b}}$ as the dependent variable and the levels of TC as independent variable. The Figure 1 showed that the levels of TC were liner with $\mathrm{HDL}_{2 \mathrm{~b}}$ contents and $\mathrm{HDL}_{2 \mathrm{~b}}$ contents can be reduced $17 \mathrm{mg} / \mathrm{L}$ for $0.5 \mathrm{mmol} / \mathrm{L}$ increment in TC. At the same time, according to ATP-III guidelines, the Chinese subjects were divided into desirable TC ( $<5.17 \mathrm{mmol} / \mathrm{L})$, borderline-high TC (5.17-6.18 mmol/ $\mathrm{L})$, and high TC ( $\geq 6.21 \mathrm{mmol} / \mathrm{L})$ groups, and observed HDL subclasses distribution profile on different TC levels that is the particles size of HDL subclasses shifted towards smaller with increased TC levels. These findings suggested that elevated TC blocked the maturation of 
HDL subclasses metabolism and the efficiency of reverse cholesterol transport (RCT) might be impeded.

Numerous investigations have documented that in hyperolesterolemic subjects, Lecithin:cholesterol acyltransferase (LCAT) activity was low while cholesterol ester transport protein (CETP) activity was high, which was associated with the increased plasma TC level in these persons [33]. The activity of LCAT is required for normal plasma lipoprotein structure and is instrumental in HDL remodeling. LCAT may catalyze unesterified cholesterol to cholesterol ester (CE) and promote the conversion of pre $\beta_{1}-\mathrm{HDL}$ and $\mathrm{HDL}_{3}$ to $\mathrm{HDL}_{2}$. CETP is a plasma hydrophobic glycoprotein made by liver and adipose that circulates in the plasma bound to lipoproteins. It mediates exchange of core lipids between very low density lipoprotein (VLDL)-TG, LDL-TG and HDLCE. The net effect of CETP action on HDL is depletion of CE and enrichment with TG, with an overall net reduction in the size of HDL particles [34].

Furthermore, we surprisingly found the distribution of HDL subclasses have shown abnormality characterized by the contents of $\mathrm{HDL}_{2 \mathrm{~b}}(324.2$ vs $379.9 \mathrm{mg} / \mathrm{L})$ decreased and the contents of pre $\beta_{1}$-HDL (90.4 vs 76.5 $\mathrm{mg} / \mathrm{L}$ ) increased significantly for desirable TC Chinese subjects compared with those for normolipidemic Chinese subjects in our previous study [9]. Why the distribution of HDL subclasses has reversed for subjects in desirable TC levels when the mean concentrations of TG, TC, and LDL-C kept the relative normal range.

Our results exhibited that there were 103 subjects with TG $<2.26 \mathrm{mmol} / \mathrm{L}$ and 107 subjects with HDL-C $\geq 1.03 \mathrm{mmol} / \mathrm{L}$ in the 176 desirable TC subjects as well as the characteristic of distribution in HDL subclass distribution for these two groups subjects was consistent with that for normolipidemic subjects [9]. On the contrary, profile of HDL subclass distribution for subjects with TG $\geq 2.26 \mathrm{mmol} / \mathrm{L}$ showed a reduced in contents of $\mathrm{HDL}_{2 \mathrm{~b}}$ (from 381.9 to $242.8 \mathrm{mg} / \mathrm{L}$ ), but an increased in contents of pre $\beta_{1}$-HDL (from 79.3 to $118.1 \mathrm{mg} / \mathrm{L}$ ) compared to the subjects with TG $<2.26 \mathrm{mmol} / \mathrm{L}$ in desirable TC levels. Similarly, the distribution of HDL subclasses for subjects with HDL-C $<1.03 \mathrm{mmol} / \mathrm{L}$ might be reversed characterized by small-sized pre $\beta_{1}$ HDL elevated while large-sized $\mathrm{HDL}_{2}$ declined.

The decreased lipoprotein lipase (LPL) and phospholipids transfer protein (PLTP) activities along with elevated hepatic lipase (HL) activity are frequently observed in higher TG levels and lower HDL-C levels. LPL cleanses triglyceride-rich lipoproteins (TRL) from circulation through its role in hydrolysis of TGs in chylomicron (CM) and VLDL. PLTP favors the formation of larger-sized HDL particles. Depletes the core of large $\mathrm{HDL}_{2}$ by $\mathrm{HL}$ and helps to form smaller $\mathrm{HDL}_{3}$ as well as lipid-free apoA-I and/or pre $\beta$-HDL. In consequence of the changes in activities of lipoprotein-modifying plasma enzymes, which resulted in the particle size of HDL subclasses tend to small. Low levels of HDL-C and elevated TG levels were associated with a high incidence of CHD. For clinical purposes, low HDL-C $(<1.03 \mathrm{mmol} / \mathrm{L})$ plus elevated TG $(\geq 2.26 \mathrm{mmol} / \mathrm{L})$ define atherogenic dyslipidemia. The relationship between HDL-C and CHD remained after adjustment for age and TG levels; where even small differences in the level of HDL-C are associated with substantial variations in the risk of major coronary events. It has been documented that cholesterol efflux is well correlated with plasma HDL-C concentrations. Data from the Framingham population indicated that, at any given level of $\mathrm{TC}$, the relative risk of CHD increases with decreasing levels of HDL-C [35]. Asztalos et al. [24] considered that altered HDL subclasses in low HDL-C subjects were prone to CHD by RCT.

It is well known that the most common hyperlipidemia for the Chinese population was characterized by elevated TG levels (ie, hypertriglyceridemia [HTG]). Our previous study displayed that HTG accounted for about $61 \%$ of total hyperlipidemia [11]. Liu suggested that HTG in China was induced by high-carbohydrate diets of the populations. High-carbohydrate diets may result in increased concentration of plasma glucose and, thus, high-insulin levels. Hyperinsulinemia stimulates the production and secretion of TG and VLDL, which lead to HTG [36].

Because of the elevated TG concentrations usually not only accompanied with reduced HDL-C, it also carried increased LDL-C concentrations. Make use a cut-point value of $3.34 \mathrm{mmol} / \mathrm{L}$ for the LDL-C to further dichotomize the Chinese subjects in desirable TC levels. The data presented that about 20 subjects with LDL-C $\geq$ $3.34 \mathrm{mmol} / \mathrm{L}$ in desirable TC levels, and the particle size of HDL subclass for these subjects tend to small. Increased levels of plasma LDL-C resulted in decreased CETP activity might be explained the alteration of HDL subclasses in subjects with LDL-C $\geq 3.34 \mathrm{mmol} / \mathrm{L}$ [37]. We also observed that among the 156 subjects with LDL-C $<3.34 \mathrm{mmol} / \mathrm{L}$, one third (52) subjects with TG $\geq 2.26 \mathrm{mmol} / \mathrm{L}-\mathrm{HDL}-\mathrm{C}<1.03 \mathrm{mmol}$, and the contents of $\mathrm{HDL}_{2 \mathrm{~b}}(215.0 \mathrm{mg} / \mathrm{L})$ reduced significantly along with those of pre $\beta_{1}$-HDL $(122.7 \mathrm{mg} / \mathrm{L})$ elevated significantly for these subjects. Collectively these findings demonstrated that distribution of HDL subclasses has reversed in desirable TC levels, especially in Chinese population.

\section{Conclusions}

Briefly, the higher TC levels, the particles size of HDL subclasses tend to small suggested that elevated TC blocked the maturation of HDL subclasses metabolism and impeded the efficiency of RCT. The TC was liner 
with $\mathrm{HDL}_{2 \mathrm{~b}}$ contents and $\mathrm{HDL}_{2 \mathrm{~b}}$ contents can be reduced $17 \mathrm{mg} / \mathrm{L}$ for $0.5 \mathrm{mmol} / \mathrm{L}$ increment in $\mathrm{TC}$ levels. The phenotype of HDL subclasses distribution was not expectation for Chinese Population with desirable TC in accordance with the ATP-III guidelines for TC levels. Thus, from the HDL subclasses distribution point, when assessing the CHD risk not only rely on the TC levels, but also the concentrations of TG, HDL-C and LDL-C must considered in case the potential risk for desirable TC subjects with other plasma lipids metabolism disorders.

\section{The abbreviations used are}

HDL: high density lipoproteins; TC: total cholesterol; ATP-III: Adult Treatment Panel-III; TG: triglyceride; LDL-C: low density lipoprotein cholesterol; CHD: coronary heart disease; HRP: horseradish peroxidase; IgG: immunoglobulin G; ANOVA: analysis of variance; RCT: reverse cholesterol transport; LCAT: lecithin: cholesterol acyltransferase; CETP: cholesterol ester transport protein; CE: cholesterol ester; VLDL: very low density lipoprotein; LPL: lipoprotein lipase; PLTP: phospholipids transfer protein; HL: hepatic lipase; TRL: triglyceride-rich lipoproteins; CM: chylomicron; HTG: hypertriglyceridemia.

\section{Acknowledgements}

We thank technician Yu Liu and master's students Jia Yao and Xuemei Zhang for the collection of the blood samples and technical support in lipid and apolipoprotein assays.

\section{Author details}

'Laboratory of Endocrinology and Metabolism, West China Hospital, Sichuan University, Chengdu 610041, Sichuan, People's Republic of China. ${ }^{2}$ Department of Biochemistry and Molecular Biology, University of South China, Hengyang, Hunan, People's Republic of China. ${ }^{3}$ Chengdu Hoist Biotechnology Co., LTD, Sichuan, PR China.

\section{Authors' contributions}

LT participated in the design of study and manuscript preparation along with editing. YHL conceived of the study, and helped to review the manuscript. MDF participated in manuscript reviewing and drafting. SYL performed the data acquisition and analysis. YHX performed data and statistics analysis. LQJ participated in drafted the manuscript. All authors read and approved the final manuscript.

\section{Notice of grant support}

This work supported by the grants from National Natural Science Foundation of China (Grant No. 30800474) and the Fundamental Research Funds for the Central Universities (Grant No. 2010SCU11029).

\section{Conflict of interests statement}

The authors declare that they have no competing interests.

Received: 28 March 2011 Accepted: 22 April 2011

Published: 22 April 2011

\section{References}

1. Fielding CJ: Lipoprotein receptors, plasma cholesterol metabolism, and the regulation of cellular free cholesterol concentration. FASEB J 1992, 6:3162-3168

2. Scann AM: Plasma lipoproteins and coronary heart disease. Annals of Clinical and Laboratory Science 1978, 8:79-88.

3. Manson JE, Tosterson H, Ridker PM, Satterfield S, Hebert P, GT O, Buring JE, Hennekens $\mathrm{CH}$ : The primary prevention of myocardial infarction. NEJM 1992, 326:1406-1416.

4. Abbott RD, Donahue RP, Kannel WB, Wilson PW: The impact of diabetes on survival following myocardial infarction in men vs women: the Framingham Study. JAMA 1988, 260:3456-3460.
5. Gordon DJ, Probstfield JL, Garrison RJ, Neaton JD, Castelli WP, Knoke JD, Jacobs DR, Bangdiwala S, Tyroler HA: High-density lipoprotein cholesterol and cardiovascular disease: four prospective American studies. Circulation 1989, 79:8-15.

6. Wilson PWF, D'Agostino RB, Levy D, Belanger AM, Silbershatz $H$, Kannel WB: Prediction of coronary heart disease using risk factor categories. Circulation 1998, 97:1837-1847.

7. Colvin PL, Parks JS: Laboratory assessment of HDL heterogeneity and function. Current opinion in Lipidology 2009, 67:7-21.

8. Jia LQ, Long SY, Fu MD, Yan BY, Tian Y, Xu YH, Gou LT, Gou LT: Relationship between total cholesterol/high-density lipoprotein cholesterol ratio, triglyceride/high-density lipoprotein cholesterol ratio, and high-density lipoprotein subclasses. Metabolism 2006, 55:1141-1148.

9. Gou LT, Fu MD, Xu YH, Tian Y, Yan BY, Yang LC: Alterations of HDL subclasses in endogenous hypertriglyceridemia. Am Heart J 2005, 150:1039-1045.

10. Yang YY, Yan BY, Fu MD, Xu YH, Tian Y: Relationship between plasma lipid concentrations and HDL subclasses. Clin Chim Acta 2005, 354:49-58.

11. $\mathrm{Xu} \mathrm{YH}, \mathrm{Fu} M D$ : Alterations of HDL subclasses in hyperlipidemia. Clin Chim Acta 2003, 332:95-102.

12. Executive Summary of the Third Report of the National Cholesterol Education Program (NCEP) Expert Panel: on Detection, Evaluation, and Treatment of High Blood Cholesterol in Adults (Adults Treatment Panel III). JAMA 2001, 285:2486-2497.

13. Warnick GR, Nguyen T, Albers AA: Comparison of improved precipitation methods for quantification of high-density lipoprotein cholesterol. Clin Chem 1985, 31:217-222.

14. Friedewald WT, Levy RI, Fredrickson DS: Estimation of the concentration of low-density lipoprotein cholesterol in plasma, without use of the preparative ultracentrifuge. Clin Chem 1972, 18:499-502.

15. Labeur C, Shepherd J, Rosseneu M: Immunological assays of apolipoproteins in plasma: methods and instrumentation. Clin Chem 1990, 36:591-597.

16. Liu BW: Immunoassay of human plasma apolipoproteins and clinical applications. In Lipoproteins and Atherosclerosis. Edited by: Wang KQ. Beijing, People's Health Press; 1995:359-368.

17. Wu XW, Fu MD, Liu BW: Study on the immunodetection method of HDL subclasses in human serum. Chin J Arterioscler 1999, 7:253-255.

18. Stamler J, Daviglus ML, Garside DB, Dyer AR, Greenland P, Neaton JD: Relationship of baseline serum cholesterol levels in 3 large cohorts of younger men to long-term coronary, cardiovascular, and all-cause mortality and to longevity. JAMA 2000, 284:311-318.

19. Neaton JD, Wentworth D: Serum cholesterol, blood pressure, cigarette smoking, and death from coronary heart disease. Overall findings and differences by age for 316099 white men. Multiple Risk Factor Intervention Trial Research Group. Arch Intern Med 1992, 152:56-64.

20. Verschuren WM, Jacobs DR, Bloemberg BP, Kromhout D, Menotti A Aravanis C, Blackburn H, Buzina R, Dontas AS, Fidanza F: Serum total cholesterol and long-term coronary heart disease mortality in different cultures. Twenty-five-year follow-up of the seven countries study. JAMA 1995, 274:131-136.

21. Sharrett AR, Ballantyne CM, Coady SA, Heiss G, Sorlie PD, Catellier D, Patsch W: Coronary heart disease prediction from lipoprotein cholesterol levels, triglycerides, lipoprotein(a), apolipoproteins A-I and B, and HDL density subfractions: The Atherosclerosis Risk in Communities (ARIC) Study. Circulation 2001, 104:1108-1113.

22. Law MR, Wald NJ, Thompson SG: By how much and how quickly does reduction in serum cholesterol concentration lower risk of ischaemic heart disease? BMJ 1994, 308:367-372.

23. Boden WE: High-density lipoprotein cholesterol as an independent risk factor in cardiovascular disease: assessing the data from Framingham to the Veterans Affairs High-Density Lipoprotein Intervention Trial. Am J Cardiol 2000, 86:19L-22L.

24. Asztalos BF, Cupples LA, Demissie S, Horvath KV, Cox CE, Batista MC, Schaefer EJ: High-density lipoprotein subpopulation profile and coronary heart disease prevalence in male participants of the Framingham Offspring Study. Arterioscler Thromb Vasc Biol 2004, 24:2181-2187.

25. McMahon M, Grossman J, FitzGerald J, Dahlin-Lee E, Wallace DJ, Thong BY, Badsha H, Kalunian K, Charles C, Navab M, Fogelman AM, Hahn BH: Proinflammatory high-density lipoprotein as a biomarker for atherosclerosis 
in patients with systemic lupus erythematosus and rheumatoid arthritis. Arthritis Rheum 2006, 54:2541-2549.

26. Otvos JD, Collins D, Freedman DS, Shalaurova I, Schaefer EJ, McNamara JR, Bloomfield HE, Rovins SJ: Low-density lipoprotein and high-density lipoprotein particle subclasses predict coronary events and are favorably changed by gemfibrozil therapy in the Veterans Affairs High-Density Lipoprotein Intervention Trial. Circulation 2006, 113:1556-1563.

27. Kulkarni KR: Cholesterol profile measurement by vertical auto profile method. In Clinics Lab Med Edited by: Smith DA 2006, 26:787-802.

28. Okazaki M, Usui S, Fukui A, Kubota I, Tomoike H: Component analysis of HPLC profiles of unique lipoprotein subclass cholesterols for detection of coronary artery disease. Clin Chem 2006, 52:2049-2053.

29. Hirayama S, Miida T, Miyazaki O, Aizawa Y: Prebeta1-HDL concentration is a predictor of carotid atherosclerosis in type 2 diabetic patients. Diabetes Care 2007, 30:1289-1291.

30. Zannis VI, Chroni A, Krieger M: Role of apoA-I, ABCA1, LCAT and SR-BI in the biogenesis of HDL. J Mol Med 2006, 84:276-294.

31. Schaefer EJ, Asztalos BF: Where are we with high-density lipoprotein raising and inhibition of cholesteryl ester transfer for heart disease risk reduction? Curr Opin Cardiol 2007, 22:373-378.

32. Remaley $\mathrm{AT}, \mathrm{MD}, \mathrm{PhD}$, is a member of the senior staff of the Department of Laboratory Medicine at the National Institutes of Health (Bethesda, Md.) and is the Section Chief of the Lipoprotein Metabolism Laboratory at the National, Heart, Lung and Blood Institute. He has served on the FDA's Chemistry and Clinical Toxicology Panel since 2002.

33. Grandjean PW, Crouse SF, James Rocks J: Influence of cholesterol status on blood lipid and lipoprotein enzyme responses to aerobic exercise. $J$ Appl Physiol 2000, 89:472-480

34. Rye KA, Clay MA, Barter PJ: Remodeling of high density lipoproteins by plasma factors. Atherosclerosis 1999, 145:227-238.

35. Castelli WP, Garrison RJ, Wilson PWF, Abbott RD, Kalousdian S, Kannel WB: Incidence of coronary heart disease and lipoprotein cholesterol levels. The Framingham Study. JAMA 1986, 256:2835-2838.

36. Liu BW: Study on the pathogenesis of endogenous hypoertriglyceridemia. Chin J Arterioscler 1993, 1:67-69.

37. Tato F, Vega GL, Tall AR: Relation between cholesterol ester transfer protein activities and lipoprotein cholesterol in patients with hypercholesterolemia and combined hyperlipidemia. Arterioscler Thromb Vasc Biol 1995, 15:112-120.

doi:10.1186/1476-511X-10-64

Cite this article as: Tian et al:: Characteristics of High-density Lipoprotein Subclasses Distribution for Subjects with Desirable Total Cholesterol Levels. Lipids in Health and Disease 2011 10:64.

\section{Submit your next manuscript to BioMed Central and take full advantage of:}

- Convenient online submission

- Thorough peer review

- No space constraints or color figure charges

- Immediate publication on acceptance

- Inclusion in PubMed, CAS, Scopus and Google Scholar

- Research which is freely available for redistribution

Submit your manuscript at www.biomedcentral.com/submit
Biomed Central 